\title{
Study on Chemical Composition of Nauclea Officinalis Leaves
}

\author{
Kui Su \\ Food College of Shihezi University \\ Shihezi, Xinjiang 832000, China \\ Oceanography College of Hainan University \\ Haikou, Hainan 570228, China \\ E-mail: 1sx20030404@163.com \\ Min Gong \& Jing Zhou \\ Food College of Shihezi University \\ Shihezi, Xinjiang 832000, China \\ Shiming Deng (Corresponding author) \\ Oceanography College of Hainan University \\ Haikou, Hainan 570228, China
}

The research is financed by the National Key Technology $R \&$ D Program. No. 2007BAI27B04 (Sponsoring information)

\begin{abstract}
Objective: The chemical composition of Nauclea officinalis leaves is analyzed to offer a theoretical base for its application. Method: Separate Nauclea officinalis leaves by solvent extraction and silica gel column, and characterize the product structure through analysis on physical properties and spectrum. Results and conclusions: 7 compounds have been separated from liposoluble part of Nauclea officinalis leaves, 5 compounds among them have been characterized, which in turn are $\beta$-sitosterol palmitate (1), stigmast-4-en-3-one (2), $\beta$-sitosterol (3), 24-en-cycloartenone (4) and bis (2-ethylhexyl) phthalate (5), wherein (1) and (4) are separated from Nauclea officinalis leaves for the first time.
\end{abstract}

Keywords: Nauclea officinalis leaves, Chemical composition, Determination of structure, Steroid

Nauclea officinalis Merr. Chun, a tree placed in Genus Nauclea of Family Rubiaceae, is found widely in Guangdong, Guangxin, Yunnan and etc. in China. Its branch, stem and root, gatherable throughout the year, are cut into small pieces and dried for the medical purpose. It is cold natured, tastes bitter, and can be used for treating exogenous fever, acute tonsillitis, laryngopharyngitis, bronchitis, pneumonia, enteritis, dysentery, acute jaundice, stomachache and etc (Deng, Shiming, 2006, p. 149). Nauclea officinalis is widely cultivated in Hainan. The existing Chinese medicines of this type distributed in the market are Nauclea Officinalis Injection and Nauclea Officinalis Extract Tablet, both from Nauclea officinalis bark. However, gathering bark is destructive to Nauclea officinalis. It is proved by the preliminary experiment and anti-microbial activity experiment that the composition of Nauclea officinalis leaves is similar to that of Nauclea officinalis bark, and there are plenty of leaves on Nauclea officinalis, therefore, the chemical composition of Nauclea officinalis leaves is systematically analyzed in this study for sustainable development and exploitation of Nauclea officinalis. 7 compounds are separated from liposoluble part of Nauclea officinalis leaves, 5 compounds among them have been characterized, which in turn are $\beta$-sitosterol palmitate (1), stigmast-4-en-3-one (2), $\beta$-sitosterol (3), 24-en-cycloartenone (4) and bis (2- ethylhexyl) phthalate, wherein (1) and (4) are separated from Nauclea officinalis leaves for the first time.

\section{Materials and instruments}

Materials for column chromatography: silica gel of 100 200/200 300 mesh from Qingdao Haiyang Chemical Co., Ltd; 
Materials for thin-layer chromatography: silica gel G/60H/GF254 from Qingdao Haiyang Chemical Co., Ltd; Gel: Sephadex LH-20 from Amersham Biosciences of Sweden. All reagents here are technical pure and used after rerun.

${ }^{1} \mathrm{H}$ NMR and ${ }^{13} \mathrm{C}$ NMR are measured respectively at $400.13 \mathrm{MHz}$ and $100.6 \mathrm{MHz}$ on Bruker AM-400.0 NMR spectrometer with TMS as internal standard. ZF-6 triple-purpose UV analyzer is provided by Jiapeng Tech. Co., Ltd. in Shanghai.

Nauclea officinalis leave is provided by Nauclea Officinalis Farm of Jinguang Pharmaceutical Group in Hainan. The sample is proved to be Nauclea officinalis Merr. Chun by Dr. Shiming Deng from the Oceanography College of Hainan University. The voucher specimens are saved in the Oceanography College of Hainan University.

\section{Methods and results}

\subsection{Extraction and separation}

Pick up fresh Nauclea officinalis leaves, dry in the shade, coarsely grind, and percolate by $95 \%$ ethanol for one week, then concentrate by pressure reduction to obtain $1.5 \mathrm{~kg}$ extractum of Nauclea officinalis leaves. The extractum is in turn extracted with petroleum ether $\left(60-90{ }^{\circ} \mathrm{C}\right)$, chloroform and ethyl acetate. Extract liquors are respectively concentrated by pressure reduction to obtain $300 \mathrm{~g}$ petroleum ether extract, $85 \mathrm{~g}$ chloroform extract and $85 \mathrm{~g}$ ethyl acetate extract, and solvents therefrom are recycled. The left water collections should pass through macroporous adsorptive resin.

$300 \mathrm{~g}$ petroleum ether extract is combined with about 7 times its weight of silica gel of 200 300 mesh, dryly fill the column and dryly load the sample, separate by gradient elution with petroleum ether/ ethyl acetate (9:1) - ethyl acetate/methanol $(1: 1)$ as eluent. Draw small dots on the origin line of the thin layer chromatography (TLC) plate. 3 bands are finally identified as the plate develops. The first band is dryly loaded and separated by gradient elution with petroleum ether / dichloromethane [1:(0 1)] as eluent to get compound 1 (20 $\mathrm{mg})$ and compound 4 (21 mg); the second band is dryly loaded after separation with Sephadex LH-20, and eluted with petroleum ether / dichloromethane to get compound 3 (200 $\mathrm{mg}$ ); the third band is dryly loaded after separation with Sephadex LH-20, and eluted with dichloromethane / ethyl acetate to get compound $2(15 \mathrm{mg})$ and compound $5(100 \mathrm{mg})$. The structures of compound $1 \sim 5$ are shown in figure 1.

\subsection{Characterization of structure and physical property}

\subsubsection{Compound 1}

Appearance: White acicular crystal (ethyl acetate).

Melting point: $88-90{ }^{\circ} \mathrm{C}$.

Formula: $\mathrm{C}_{45} \mathrm{H}_{80} \mathrm{O}_{2}$.

${ }^{1} \mathrm{H}$ NMR $\left(400 \mathrm{MHz}, \mathrm{CDCl}_{3}\right) \delta: 5.38(1 \mathrm{H}, \mathrm{d}, \mathrm{J}=4.8 \mathrm{~Hz}), 4.62(1 \mathrm{H}, \mathrm{m}), 1.28$ [br.s, $\left.\left(\mathrm{CH}_{2}\right)_{\mathrm{n}}\right], 1.04(3 \mathrm{H}, \mathrm{s}), 0.80 \sim 0.93(\mathrm{~m}$, $\left.\left(\mathrm{CH}_{3}\right)_{5}\right), 0.69\left(3 \mathrm{H}, \mathrm{s}, \mathrm{CH}_{3}\right)$.

${ }^{13} \mathrm{C}$ NMR (100 MHz, $\mathrm{CDCl}_{3}$ ) $\delta: 37.0$ (C-1), 27.8 (C-2), 73.7 (C-3), 38.2 (C-4), 139.7 (C-5), 122.6 (C-6), 31.9 (C-7, C-8), 50.0 (C-9), 36.6 (C-10), 21.0 (C-11), 39.8 (C-12), 42.3 (C-13), 56.7 (C-14), 24.3 (C-15), 28.2 (C-16), 56.1 (C-17), 11.8 (C-18), 19.3 (C-19), 36.2 (C-20), 18.8 (C-21), 34.0 (C-22), 26.2 (C-23), 45.9 (C-24), 29.1 (C-25), 19.8 (C-26), 19.0 (C-27), 23.1 (C-28), 12.0 (C-29); Aliphatic chain part: 173.3 (C-1'), 34.7 (C-2'), 25.1 (C-3'), 29.2 29.7 (C-4' C-13'), 31.9 (C-14'), 22.7 (C-15'), 14.1 (C-16'). ${ }^{13} \mathrm{C}$ NMR spectrum indicates a signal of carbon and a signal of fatty acyl carbon of $\beta$-sitosterol.

Above-mentioned data are in accordance with the reference-reported spectrum data of $\beta$-sitosterol palmitate (Dong, Xue, 2008, p. 63-66; Huang, Ping, 2008, p. 271-274). Therefore, it can be concluded that the compound 1 is $\beta$-sitosterol palmitate.

\subsubsection{Compound 2}

Appearance: Colorless oily matter; non-fluorescence at $254 \mathrm{~nm}$ under UV lamp after developing on TLC; grey in 10\% sulfuric acid-ethanol solution.

Formula: $\mathrm{C}_{29} \mathrm{H}_{48} \mathrm{O}$.

${ }^{1} \mathrm{H}$ NMR (400.13 MHz, $\mathrm{CDCl}_{3}$ ) spectrum indicates six $\mathrm{H}$ signals of methyl group in $\delta 0.71 \sim 1.18$, an olefinic $\mathrm{H}$ signal of 4-double bond at low field range $[\delta 5.72(1 \mathrm{H}, \mathrm{s}, \mathrm{H}-4)]$. Signals at $\delta 5.72(1 \mathrm{H}, \mathrm{s}, 4-\mathrm{H})$ and $\delta 2.38 \sim 1.30$ correspond to hydrogen on the backbone and side chain respectively. Assignments of the rest signals are as following: 1.18 (s, $3 \mathrm{H}$, $\left.19-\mathrm{CH}_{3}\right), 0.92$ (d, 3H, J=6.4 Hz, 29- $\left.\mathrm{CH}_{3}\right), 0.82 \sim 0.84\left(9 \mathrm{H}, \mathrm{m}, 3 \mathrm{CH}_{3}-21,26,27\right), 0.71\left(3 \mathrm{H}, \mathrm{S}, \mathrm{CH}_{3}-18\right)$.

${ }^{13} \mathrm{C}$ NMR $\left(100.6 \mathrm{MHz}, \mathrm{CDCl}_{3}\right)$ spectrum indicates 29 carbon signals in total with 1 carbon signal of carbonyl group at low field range $(\delta$ 198.5) and 2 carbon signals of olefinic carbon at $\delta 122.7 / 170.5$. Therefore, it is determined that compound 2 is a steroid. Assignments of above-mentioned ${ }^{13} \mathrm{C}$ NMR signals are as following: $\delta 34.8(\mathrm{t}, \mathrm{C}-1), 32.8(\mathrm{t}$, C-2), 198.5 (s, C-3), 122.7 (d, C-4), 170.5 (s, C-5), 31.9 (t, C-6), 31.0 (t, C-7), 34.6 (d, C-8), 52.7 (d, C-9), 37.5 (s, 
C-10), 22.0 (t, C-11), 38.5 (t, C-12), 41.3 (s, C-13), 54.9 (d, C-14), 25.0 (t, C-15), 27.1 (t, C-16), 54.9 (d, C-17), 10.9 (q, C-18), 18.0 (q, C-19), 35.0 (d, C-20), 16.3 (q, C-21), 32.9 (t, C-22), 23.1 (t, C-23), 44.7 (d, C-24), 27.1 (d, C-25), 18.7 (q, C-26), 17.6 (q, C-27), 23.1 (t, C-28), 10.9 (q, C-29).

Above-mentioned data are in accordance with the reference-reported spectrum data of stigmast-4-en-3-one (Xuan, Weidong, 2005). Therefore, it can be concluded that the compound 2 is stigmast-4-en-3-one.

\subsubsection{Compound 3}

Appearance: White acicular crystal (chloroform); non-fluorescence at $254 \mathrm{~nm}$ under UV lamp after developing on TLC; red in 10\% sulfuric acid-ethanol solution.

Formula: $\mathrm{C}_{29} \mathrm{H}_{50} \mathrm{O}$.

${ }^{1} \mathrm{H}$ NMR (400.13 MHz, $\mathrm{CDCl}_{3}$ ) spectrum indicates six $\mathrm{H}$ signals of methyl group in $\delta 0.67 \sim 1.00$, an olefinic hydrogen signal of 6-double bond at low field range $[\delta 5.35(1 \mathrm{H}$, br.s, H-6)]. Signals at $\delta 5.35(\mathrm{~d}, 1 \mathrm{H}, \mathrm{J}=5.2 \mathrm{~Hz}, 6-\mathrm{H}), 3.56(\mathrm{~m}, 1 \mathrm{H}$, $3-\mathrm{H})$ and 2.27 1.49 correspond to hydrogen on the backbone and side chain respectively. Assignments of the rest signals are as following: $1.00\left(\mathrm{~s}, 3 \mathrm{H}, 19-\mathrm{CH}_{3}\right), 0.91\left(\mathrm{~d}, 3 \mathrm{H}, \mathrm{J}=6.9 \mathrm{~Hz}, 29-\mathrm{CH}_{3}\right), 0.81-0.84\left(9 \mathrm{H}, \mathrm{m}, 3 \mathrm{CH}_{3}-21,26,27\right)$, $0.67\left(3 \mathrm{H}, \mathrm{S}, \mathrm{CH}_{3}-18\right)$.

${ }^{13} \mathrm{C}$ NMR $\left(100.6 \mathrm{MHz}, \mathrm{CDCl}_{3}\right.$ ) spectrum indicates 29 carbon signals in total with 1 carbon signal of hydroxyl group at medium field range $(\delta 71.8)$ and 2 carbon signals of olefinic carbon at $\delta 140.7 / 121.7$. Therefore, it is determined that compound 3 is a steroid. Assignments of above-mentioned ${ }^{13} \mathrm{C}$ NMR signals are as following: $\delta 37.3(\mathrm{t}, \mathrm{C}-1), 31.9(\mathrm{t}$, C-2), 71.8 (d, C-3), 40.5 (t, C-4), 140.7 (s, C-5), 121.7 (d, C-6), 31.9 (t, C-7), 31.6 (d, C-8), 50.2 (d, C-9), 36.5 (s, C-10), 21.1 (t, C-11), 39.8 (t, C-12), 42.3 (s, C-13), 56.8 (d, C-14), 24.3 (t, C-15), 28.3 (t, C-16), 56.1 (d, C-17), 11.9 (q, C-18), 19.5 (q, C-19), 36.2 (d, C-20), 18.9 (q, C-21), 33.9 (t, C-22), 26.1 (t, C-23), 45.8 (d, C-24), 29.1 (d, C-25), 19.4 (q, C-26), 19.1 (q, C-27), 23.1 (t, C-28), 12.0 (q, C-29).

Above-mentioned data are in accordance with the reference-reported spectrum data of $\beta$-sitosterol (Liu, Zhiping, 2007 , p. 140-142). Therefore, it can be concluded that the compound 3 is $\beta$-sitosterol.

\subsubsection{Compound 4}

Appearance: White acicular crystal (chloroform); non-fluorescence at $254 \mathrm{~nm}$ under UV lamp after developing on TLC; red in $10 \%$ sulfuric acid-ethanol solution.

Formula: $\mathrm{C}_{30} \mathrm{H}_{48} \mathrm{O}$.

The EI-MS shows characteristic peaks at $440[\mathrm{M}]^{+}, 424[\mathrm{M}-\mathrm{O}]^{+}, 409\left[\mathrm{M}-\mathrm{O}-\mathrm{CH}_{3}\right]^{+}, \mathrm{m} / \mathrm{z}, 440,424,409,395,380,355,270$, 205, 175, 147, 107, 95, 69, 55.

${ }^{1} \mathrm{H}$ NMR (400.13 MHz, $\mathrm{CDCl}_{3}$ ) spectrum indicates two $\mathrm{H}$ signals of 19-methylene group in cycloartane triterpenoids at high field range $[\delta 0.58(1 \mathrm{H}, \mathrm{d}, \mathrm{J}=4.4 \mathrm{~Hz}, \mathrm{H}-19)$ and $\delta 0.78(1 \mathrm{H}, \mathrm{d}, \mathrm{J}=4.3 \mathrm{~Hz}, \mathrm{H}-19)]$, seven $\mathrm{H}$ signals of methyl group in $\delta 0.88 \sim 1.73$, and an olefinic hydrogen signal of 24-double bond at low field range $[\delta 5.10(1 \mathrm{H}$, br.s, $\mathrm{H}-24)]$.

${ }^{13} \mathrm{C}$ NMR $\left(100.6 \mathrm{MHz}, \mathrm{CDCl}_{3}\right.$ ) spectrum indicates 30 carbon signals in total with 1 carbon signal of ketone group at low field range ( $\delta 216.6$ ) and 2 carbon signals of olefinic carbon at $\delta 130.9 / 125.2$. Therefore, it is determined that compound 4 is a 9, 19-cycloartane triterpenoids. Assignments of above-mentioned ${ }^{13} \mathrm{C}$ NMR signals are as following: $\delta 216.6$ (C-3), 130.9 ( C-25), 125.2 (C-24), 52.3 (C-17), 50.2 (C-4), 48.7(C-14), 48.4 (C-5), 47.9 (C-8), 45.3 (C-13), 37.5(C-2), 36.3 (C-22), 35.8 (C-20), 35.5 (C-15), 33.4 (C-1), 32.8 (C-12), 29.5 (C-19), 28.1(C-7), 26.7 (C-16), 25.9 (C-10), 25.8 (C-11), 25.7 (C-27), 24.9 (C-23), 22.1 (C-30), 21.5 (C-6), 21.1 (C-9), 20.7 (C-29), 19.3 (C-18), 18.2(C-28), 18.0 (C-21), $17.6(\mathrm{C}-26)$.

Above-mentioned data are in accordance with the reference-reported spectrum data of 24-en-cycloartenone (Wang, Wenze, 2006, p. 91-92). Therefore, it can be concluded that the compound 4 is 24-en-cycloartenone.

\subsubsection{Compound 5}

Appearance: Yellow oily matter; from red to purple in 10\% sulfuric acid-ethanol solution.

Formula: $\mathrm{C}_{24} \mathrm{H}_{38} \mathrm{O}_{4}$.

${ }^{1} \mathrm{H}$ NMR (400 MHz, $\mathrm{CDCl}_{3}$ ) spectrum indicates characteristic peaks at $\delta 4.12(2 \mathrm{H}, \mathrm{m}), 1.69(1 \mathrm{H}, \mathrm{m}), 1.27 \sim 1.47(8 \mathrm{H}, \mathrm{m})$, $0.89(3 \mathrm{H}, \mathrm{t}, \mathrm{J}=7.5 \mathrm{~Hz}), 0.93(3 \mathrm{H}, \mathrm{t}), 7.74(1 \mathrm{H}, \mathrm{m}), 7.64(1 \mathrm{H}, \mathrm{m})$.

${ }^{13} \mathrm{C}$ NMR $\left(100 \mathrm{MHz}, \mathrm{CDCl}_{3}\right)$ spectrum indicates characteristic peaks at $\delta 68.3(\mathrm{t}, \mathrm{C}-1), 39.6(\mathrm{~d}, \mathrm{C}-2), 31.1(\mathrm{t}, \mathrm{C}-3), 23.6$ (t, C-4), 29.7 (t, C-5), 14.3 (q, C-6), 24.7 (t, C-7), 11.3 (q, C-8), 167.9 (s, C=O), 133.4 (s, C-1'), 129.6 (d, C-2’), 131.9 (d, C-3').

Above-mentioned data are in accordance with the reference-reported spectrum data of bis (2-ethylhexyl) phthalate (Deng, Shiming, 2002, p. 99). Therefore, it can be concluded that the compound 5 is bis (2-ethylhexyl) phthalate. 


\section{Discussion}

Reports on the chemical composition of Nauclea officinalis have been mainly about its bark. However, this paper preliminarily studies the chemical composition of Nauclea officinalis leaves, especially its low polar parts. The separated main products are steroid. There have been abundant reports (Jie, Fei, 2006) on Nauclea officinalis barks which demonstrate that the main constituents of Nauclea officinalis are alkaloid and triterpene. Xuan (2005) reported that the anti-bacterial component in Nauclea officinalis is alkaloid. However, this study on the low polar part of ethanol extract from Nauclea officinalis leaves indicates no alkaloid in them. Therefore, the issues that if there is great difference in chemical composition between leave and bark of Nauclea officinalis, especially if there is the same alkaloid in leave as that in bark, and if the separated compounds in this study have the same anti-bacterial activity should be addressed in the future study.

\section{References}

Deng, Shiming. (2002). Chemical constituents of five medicinal plants. Doctoral Dissertation from Graduate University of Chinese Academy of Sciences, 6, 99.

Deng, Shiming. (2006). The List of Common Chinese Herbal Medicine in Hainan. Beijing: Chinese Science and Technology Publisher. p. 149.

Dong, Xue, Wang, Guorong \& Yao, Qingqiang. (2008). Chemical constituents of Sparganium stoleniferum. Acta Pharmaceutica Sinica, 43(1), 63-66.

Huang, Ping, Karagianis Gloria, Wei, Shanxin \& Waterman Peter G. (2008). Chemical constituents in the heartwood of Paulownia kawakamii. Natural Product Research and Development, 20(2), 271-274.

Liu, Zhiping, Cui, Jianguo, Liu, Hongxing, Huang, Chusheng \& Zhong, Zhenguo. (2007). Chemical constituents from leaves of Livistona chinensis. Guihaia, 27(1), 140-142.

Wang, Wenze, Zhao, Yuqing \& Li, Xian. (2006). Chemical constituents from seeds of Zanthoxylum bungeanum maxim. Journal of Shenyang Pharmaceutical University, 23(2), 91-92.

Xie, Fei. (2006). Studies on chemical constituents and fingerprints of Nauclea officinalis. MS Dissertation from Shandong University, 8.

Xuan, Weidong. (2005). Studies on bioactive constituents of Nauclea officinalis and Ervatamia yunnanensis. Doctoral Dissertation of the Second Military Medical University.

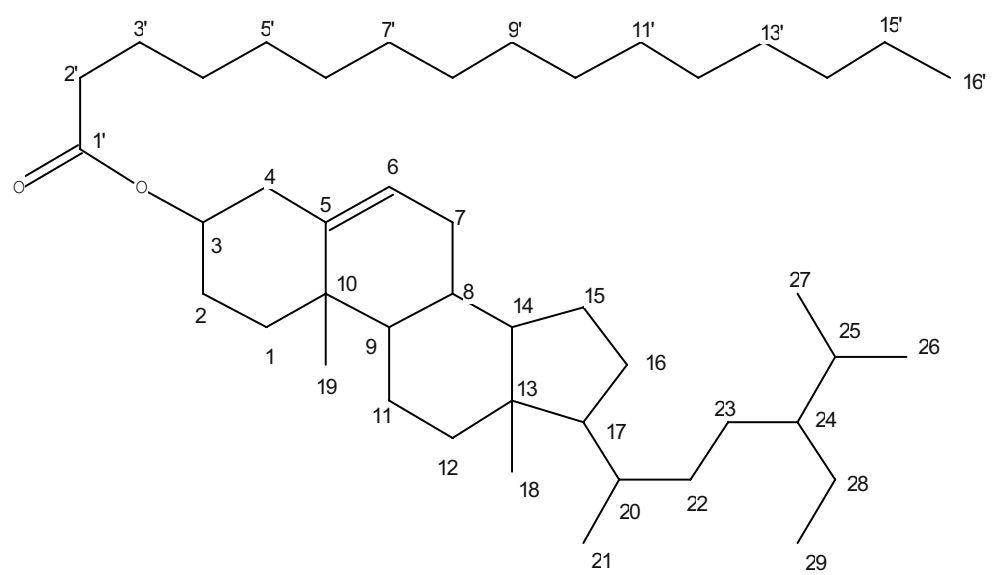

(1) $\beta$-sitosterol palmitate 


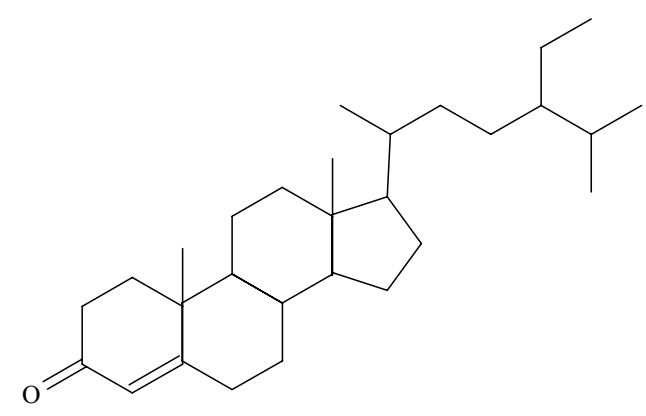

(2) Stigmast-4-en-3-one<smiles>CCC(CCC(C)C1CCC2C3CC=C4CC(O)CCC4(C)C3CCC12C)C(C)C</smiles>

(3) $\beta$-sitosterol<smiles>CC(C)=CCCC(C)C1CCC2(C)C3CCC4C(C)(C)C(=O)CCC45CC35CCC12C</smiles>

(4) 24-en-cycloartenone<smiles>CCCCC(CC)COC(=O)c1ccccc1C(=O)OCC(CC)CCCC</smiles>

(5) Bis (2-ethylhexyl) phthalate

Figure 1. Structures of compound 1 5 


\title{
Research on Antifouling and Easy Decontaminating
}

\author{
by a New Method
}

\author{
Xiaojie Liang \& Jinbo Yao \\ Textile College, Tianjin Polytechnic University \\ Tianjin 300160 China \\ E-mail: linshaohan2003@163.com
}

\begin{abstract}
Study the effect of blending hydrophilic agent and water and oil repellent agent on cotton fabric property of antifouling and easy decontaminating. The study shows that blending could make the fabric have property of antifouling and easy decontaminating.
\end{abstract}

Keywords: Antifouling and easy decontaminating, Blend, Cotton fabric

\section{Introduction}

For many years, workers had done plenty of researches on fabric of water and oil proofing. fluorine-contained finishing agent has been received much attention for its excellent property of water and oil repellent, soil release (Zhen.Wan, 2005).

For overcoming the disadvantages of the single water and oil repellent or soil release finishing, the agent which contains oil repellency chain segment and hydrophilic segment was developed out. The fabric which finished by this agent can have the property of water and oil repellent on dry, and the soil release property on wet (Shungen, Zhu, 1997). At present, soil release finish agent is almost copolymer compounds which contain hydrophilic part and water and oil repellent part (Zhijun. Zhang, 2004). This finishing agent high in price and is synthesis complexly. So it is necessary to search a new method to reach the effect of antifouling and soil release property. Fluorine part of this copolymer soil release finishing agent play a role in water and oil repellent on dry, hydrophilic part plays a role in soil release in wet. So we can think that can we mix the water and oil repellent agent and hydrophilic agent to reach the same effect as the copolymer antifouling and soil release finishing agent? Use macroscopic method to solve microscopic problem, so this can reduce cost greatly.

\section{Experiment}

\subsection{Experimental material}

Cotton plain weave cloth, water and oil repellent finishing agent (FK-510), moisture adsorption and perspiration exhaust finishing agent( FK-829).

\subsection{Equipment}

Double roll padder (switzerland), YHW-102 dry box (changsha,china), whiteness instrument(U.S.A datacolor company), contact angle instrument(chengde, china)

\subsection{Technological processes}

Double-dipdouble-nip $\rightarrow$ drying $\left(100^{\circ} \mathrm{C} \times 1.5 \mathrm{~min}\right) \rightarrow$ baking $\left(160^{\circ} \mathrm{C} \times 3 \mathrm{~min}\right) \rightarrow$ washing $\rightarrow$ drying

Finishing prescription: $\quad$ FK-510: $60 \mathrm{~g} / \mathrm{L}$

$$
\text { FK-829: Xg/L }
$$

$<$ Table 1 $>$

\subsection{Test}

Grade evaluation of water and oil repellent uses PRC professional standard ZB W 04015-89. 